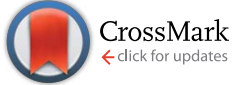

Cite this: RSC Adv., 2017, 7, 7108
Received 31st October 2016 Accepted 27th December 2016

DOI: $10.1039 / \mathrm{c} 6 \mathrm{ra26068c}$

www.rsc.org/advances

\section{Hydrophilic nanofibrous composite membrane prepared by melt-blending extrusion for effective separation of oil/water emulsion $\uparrow$}

\begin{abstract}
Dandan Xu, Xiaoting Zheng and Ru Xiao*
A polyethylene-co-polyvinyl alcohol (EVOH) nanofiber membrane was prepared by the melt blending extrusion and high-speed airflow deposition process. Then nano cellulose crystal/polyethylene-copolyvinyl alcohol (NCC/EVOH) nanofiber composite membranes were obtained via coating and depositing the barrier layer on the surface of the nanofiber membrane. The basic structural properties and oil-water separation performance of the composite membranes were investigated. The results show that the deposited NCC formed a dense layer in the surface of the nanofiber membrane with smaller pore size, and had no effect on the continuous pore structure of the membrane. With increasing NCC content, the composite membranes showed an increase of tensile strength (from 9.969 MPa to 12.991 $\mathrm{MPa}$ ) and a decrease of contact angle, pore size, and water flux. The water flux and the filtration flux of the composite membrane can be improved within a certain range by increasing the operating pressure. The NCC/EVOH nanofiber composite membranes were successfully applied for the separation of oilwater emulsion and exhibited a higher rejection rate (99.5\%). Moreover, the NCC/EVOH nanofiber composite membranes possessed a higher recovery rate of filtration flux than unmodified $\mathrm{EVOH}$ nanofiber membranes and the commercial micro-filtration membranes.
\end{abstract}

\section{Introduction}

Oily wastewater derives from industries such as crude oil production, oil and gas extraction, oil refineries, petrochemicals, lubricants, cooling agents, and metallurgical. ${ }^{1-3}$ Because of the low surface tension, oil in oily wastewater is prone to contaminate the surface of the surrounding environment, such as the transport equipment and engineering systems. In addition, oil in oily wastewater may cause serious problems to the aquatic environment and lives due to the insufficient oxygen supply. Hence, effective removal of oil from oily wastewater is one of the very important issues for pollution control in the current world. ${ }^{4}$ Oil exists in several forms in the oily wastewater as it is classified into three classes, free oil (oil droplet size $>150$ $\mu \mathrm{m})$, dispersed oil $(20 \mu \mathrm{m}<$ oil droplet size $<150 \mu \mathrm{m})$ and emulsified oil (oil droplet size $<20 \mu \mathrm{m}$ ). The U.S. Environmental Protection Agency (EPA) stipulates that the produced water discharge should contain less than a concentration of $29 \mathrm{ppm}^{5}$

Many conventional techniques exist for the separation of oilwater emulsions such as microwave heating, gravity separation, adsorption, flotation and centrifugal separation. ${ }^{6,7}$ Those

State Key Laboratory for Modification of Chemical Fibers and Polymer Materials, College of Materials Science and Engineering, Donghua University, Shanghai 201620, P. R. China. E-mail: xiaoru@dhu.edu.cn

$\dagger$ Electronic supplementary information (ESI) available. See DOI: $10.1039 / \mathrm{c} 6 \mathrm{ra} 26068 \mathrm{c}$ processes may effectively remove free and dispersed oil but not the emulsified. Besides, the conventional separation systems usually require large occupancy space and high operating cost, and have limited application in small and medium platforms. ${ }^{8}$

The membrane technique has proved to be one of the best methods for the separation of oil-water emulsions and has gained popularity over the last few decades. ${ }^{9}$ Membrane technique for oil/water separation has the potential to provide a simple system with high separation efficiency for oily wastewater treatment. Due to specific properties of remarkable specific surface area, high porosity, small pore size, and interconnected pore structure, nanofiber membrane is considered to be a very promising membrane technique material.

Many methods have been developed to prepare nanofibers, including electrospinning, ${ }^{\mathbf{1 0}-13}$ polymerization, melt blowing, cold drawing, centrifugal force spinning, ${ }^{14-18}$ phase separation $^{19-21}$ and melt blending extrusion. ${ }^{22-24}$ Most polymer resins used for this purpose are thermoplastic polyolefins or polyesters, which can be melted and reprocessed. The melt blending extrusion which is one of the effective methods for preparing various kinds of thermoplastic polymer nanofibers is environment friendly, high efficiency, versatility and continuous. ${ }^{25}$ Recently, the fabrication of fibrous membranes with large specific surface area and high porosity via melt blending extrusion has been widely studied. ${ }^{26-28}$ In the melt blending extrusion process, the dispersed phase is stretched into nanofibers. Then the thermoplastic polymer nanofibrous membranes are obtained after the 
matrix phase is removed. Surface hydrophilicity is a critical feature of oil-water separation membranes. However, conventional nanofibrous membranes with poor hydrophilicity surfaces are usually subject to fouling and pore clogging by oil droplets, which has greatly limited the application of membrane technology in oily wastewater management so far. Separation membranes with high surface hydrophilicity can improve the affinity of water to membrane surface, so that increase the water diffusion rate. Recently, emphasis has been placed on materials with excellent wettability. ${ }^{29,30}$ Some methods have been carried out to improve hydrophilicity, like surface graft copolymerization, plasma treatment or coating with synthetic polymers. However, these attempts have several disadvantages such as low efficiency, complicated operation process and high operation costs. ${ }^{31,32}$ What's more, it is significant to shift to natural, renewable and biodegradable resources due to the lack of fossil energy. ${ }^{33}$

Cellulose as a material for membrane technology has attracted much interest in water treatment for years, which is one of the most versatile and widely found natural raw material in the world. Over the past decade, a large number of studies have been reported that the nano crystalline cellulose (NCC) $(<100 \mathrm{~nm})$, separated from natural cellulose effectively and completely by physical and chemical methods. ${ }^{34,35}$ One recent trend, NCC was added to the material as the functional components, to improve the hydrophilicity, material mechanical properties and biocompatibility. ${ }^{36-40}$ Nanofiber composite membranes can be prepared by introducing NCC on the surface of nanofiber membrane, and present better application in liquid filtration.

In this study, polyethylene-co-polyvinyl alcohol (EVOH) nanofiber membrane was prepared by the method of melt blending extrusion. Then NCC/EVOH nanofiber composite membranes (N/E-NCM) were obtained via coating and deposition the barrier layer on the surface of the nanofiber membrane scaffold supported on PET nonwoven fabric. The basic structure properties including the surface morphology, wettability, pore size distribution and water flux of N/E-NCM was investigated. Above all, the filtration performance of N/E-NCM for oil-water emulsion was studied systematically.

\section{Materials and methods}

\subsection{Materials}

Poly(ethylene-co-vinyl alcohol) (EVOH, Model: ET3803) with 38 mol\% ethylene was supplied by Nippon Gohsei, Japan. Cellulose acetate butyrate ester (CAB, Model: 381-20, butyryl content $37 \mathrm{wt} \%$, acetyl content $13.5 \mathrm{wt} \%$ and hydroxyl content $1.8 \mathrm{wt} \%$ ) was purchased from the Eastman Chemical Company (U.S.A). Nano cellulose crystal (NCC, diameter 7-10 nm, particle size 200 $\mathrm{nm}$ ) was purchased from Beijing Nanocrystalline Cellulose Technology Research \& Development Centre. Titanium dioxide (99.8\%, $100 \mathrm{~nm}$, anatase, hydrophilic) was purchased from Aladdin (Shanghai, China). Acetone (AR, $0.7845 \mathrm{~g} \mathrm{~cm}^{-3}$ ) was purchased from Yanshan Petrochemical Industries Co. WX mixed cellulose ester microporous membrane (pore size 0.22 $\mu \mathrm{m})$ as the reference film was purchased from Shanghai Peninsula Industrial Co., Ltd.

\subsection{Preparation}

2.2.1 Preparation of EVOH nanofibers membrane. EVOH nanofibers were prepared according to a previously published procedure. ${ }^{24}$ EVOH was dried in electric heating air-blowing drier for $24 \mathrm{~h}$ at $80{ }^{\circ} \mathrm{C}$ and the other materials were dried in vacuum drying oven for $24 \mathrm{~h}$ at $100{ }^{\circ} \mathrm{C}$ before melt blending extrusion. $\mathrm{EVOH} / \mathrm{CAB}$ blends with the weight ratios of $20 / 80$ were fed into the co-rotating twin-screw extruder $(D=16 \mathrm{~mm}$, $L / D=40$, EUROLAB16, Thermo-Haake Co.) with a screw speed of $50 \mathrm{rpm}$ and melting zone temperature were 200 to $225^{\circ} \mathrm{C}$ for $\mathrm{EVOH} / \mathrm{CAB}$. The blends were extruded by a take-up device and water-cooled to room temperature. Then the extrudants were immersed in acetone via a Soxhlet extractor at room temperature for $24 \mathrm{~h}$ to remove $\mathrm{CAB}$ from the blends. After removing the matrix phase $\mathrm{CAB}$, EVOH nanofibers were obtained for the following preparation of $\mathrm{EVOH}$ nanofibers membrane.

The prepared EVOH nanofibers were dispersed using a mechanical disintegrator for $30 \mathrm{~s}$ to obtain a consistent fiber suspension, and then a layer of the fibers was deposited onto a supporting polyethylene terephthalate (PET) nonwoven mat $\left(30 \mathrm{~g} \mathrm{~m}^{-2}\right)$. After natural drying for $24 \mathrm{~h}$ under ambient condition, the EVOH nanofibers $\left(16 \mathrm{~g} \mathrm{~m}^{-2}\right)$ membrane was obtained with a controlled thickness (Fig. S1†).

2.2.2 Preparation of NCC/EVOH nanofibers composite membrane. The NCC was introduced to gain NCC/EVOH nanofiber composite membrane (N/E-NCM). NCC was dissolved in water and dispersed by ultrasonic dispersion to obtain NCC homogeneous suspension (0.4 wt\%). N/E-NCM was prepared by depositing NCC onto the surface of EVOH nanofiber membrane with the role of water flow, then dried for $10 \mathrm{~min}$ at $100{ }^{\circ} \mathrm{C}$. When the amount of NCC were $0,15,20,25$, $30 \mathrm{mg} \mathrm{cm} \mathrm{cm}^{-3}$, it was marked as $\mathrm{N}-0, \mathrm{~N}-1, \mathrm{~N}-2, \mathrm{~N}-3, \mathrm{~N}-4$ correspondingly.

\subsection{Measurement and characterization}

2.3.1 Morphology and structure. The morphology of N/ENCM was characterized using scanning electron microscopy (SEM, S-3000N, Hitachi, Ltd., Japan). The chemical characteristics of N/E-NCM were determined by Fourier transform infrared spectroscopy (FT-IR, Nicolet Nexus 8700), and the result was shown in Fig. $\mathrm{S} 2 . \dagger$

2.3.2 Wettability. Water contact angle measurement with water volume $3 \mu \mathrm{l}$ was performed using a contact angle goniometry (OCA 40 Micro, Dataphysics Ltd., Germany) to evaluate wettability of N/E-NCM.

2.3.3 Pore size distribution. The pore sizes and pore size distributions of N/E-NCM were examined using a capillary flow porometer (CFP-1100AI, Porous Materials Inc., USA).

2.3.4 Stress-strain properties. The nanofiber membranes were cut into $70 \mathrm{~mm} \times 10 \mathrm{~mm}$ swatches. The stress-strain curves of the swatches were measured used a Materials Testing System (AGS-500ND, SHIMADZU, Japan) with the effective test length of $50 \mathrm{~mm}$ and the test speed of $10 \mathrm{~mm} \mathrm{~min}^{-1}$. 
2.3.5 Water flux. A crossflow filtration device (self-made) was used to measure the pure water flux of corresponding membrane. The effective membrane area was $4.1 \mathrm{~cm}^{2}$. The membranes should be prepressed with inlet pressure $0.1 \mathrm{MPa}$ for $30 \mathrm{~min}$ before flux test. This experiment was repeated 5 times and the average value was taken.

The pure water penetration flux was defined as the following eqn (1):

$$
J=\frac{Q}{A T}
$$

where $J$ is the pure water flux of corresponding membrane (L $\left.\mathrm{m}^{-2} \mathrm{~h}^{-1}\right), Q$ is the volume of permeate water $(\mathrm{L}), A$ is the effective area of the membrane $\left(\mathrm{m}^{2}\right), T$ is the permeation time (h).

2.3.6 Oil-water separation performance. In order to evaluate the filtration properties of N/E-NCM, oil-in-water emulsions were prepared using corn oil. The separation test was carried out at a preset pressure using wetted N/E-NCM. The pure water flux was first tested, followed by the separation of oil-inwater emulsion. These tests were repeated 3 times and the average value was taken.

Since the oil-in-water emulsion used was stable and the particle size distributions of oil particles were very narrow, the effect of diameter variance on the adsorption intensities measured for different samples with UV-Vis spectrometer could be offset. The oil content in emulsion before and after filtration were measured by a UV-Vis spectrophotometer (Lambda 35 PerkinElmer, USA) with wavelength between 190 and $400 \mathrm{~nm}$. The UV standard curve for oil-water emulsion was presented in Fig. S3. $\uparrow$ The rejection ratio was calculated by the following eqn (2):

$$
R(\%)=\frac{\left(C_{\mathrm{f}}-C_{\mathrm{p}}\right)}{C_{\mathrm{f}}} \times 100
$$

where $C_{\mathrm{f}}$ is the concentration of prepared oil-in-water emulsion before filtration, $C_{\mathrm{p}}$ is the concentration of oil-in-water emulsion after filtration.

\section{Result and discussion}

\subsection{Morphology and structure}

Fig. 1 displays the SEM images of the surface of N/E-NCM with different NCC content. EVOH nanofibers with short length and disorderly distribution were broken by high-speed dispersion process. EVOH nanofiber membranes were obtained by the high-speed airflow deposition, revealing randomly oriented three-dimensional (3D) nonwoven structures. As shown in Fig. 1a and e, at low content of NCC, EVOH nanofibers with large diameter play a supporting role, forming a network as scaffolds, while the NCC nanofibers with small diameter deposited on the surface and network of the EVOH nanofibers. With the increasing of NCC content, the NCC accumulated on the surface of EVOH nanofiber membrane gradually (Fig. 1b).

As shown in Fig. 1c, as the amount of NCC increased to $25 \mathrm{mg} \mathrm{cm}^{-3}$, a thin layer of NCC has been formed on the surface of nanofiber membrane. While as the content of NCC increased
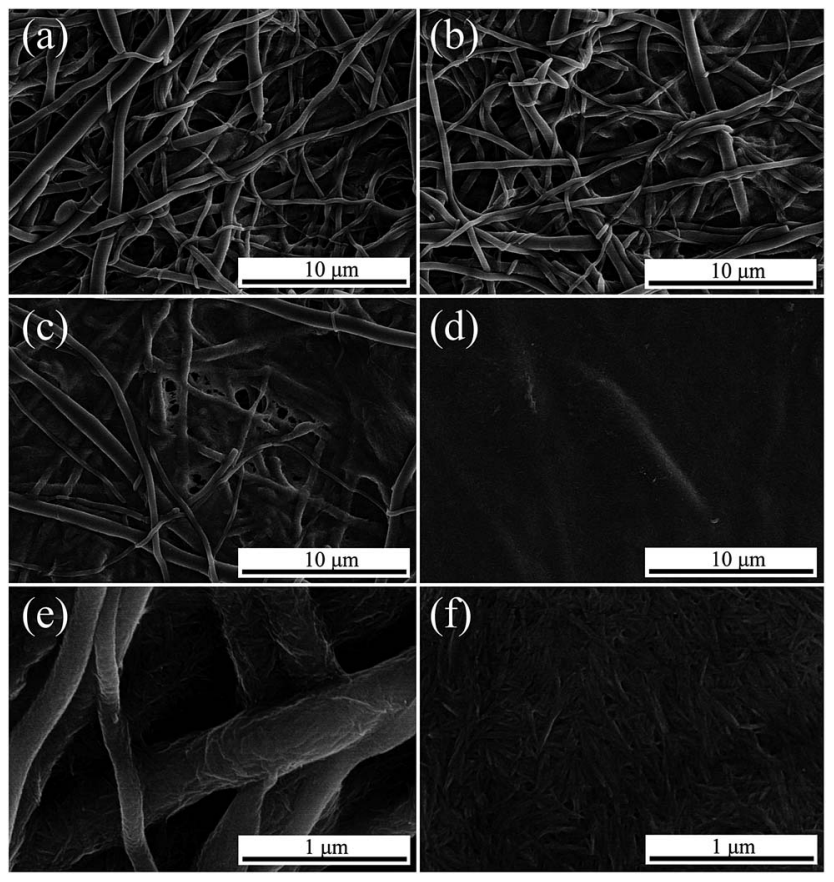

Fig. 1 SEM images of surface morphology of NCC/EVOH nanofiber composite membrane (a) and (e) N-1, (b) N-2, (c) N-3, (d) and (f) N-4.

to $30 \mathrm{mg} \mathrm{cm}^{-3}$, the NCC covered EVOH nanofiber membrane surface completely, forming the NCC barrier layer. The strong interaction force devoted to the NCC dense layer was owing to the nanoscale effects between nanofibers and NCC.

Fig. 2 presents the cross-section morphology of N/E-NCM with various NCC content by SEM. As illustrated in the Fig. 1, the barrier layer and the mid-layer that possessed a porous structure to reduce the resistance to water flow. The membrane porosity decreased gradually from bottom to top, and the neighboring small pores were interconnected. At low NCC content, only a small amount of ultrafine NCC loaded on EVOH nanofiber membrane surface and in the voids. With the increasing of the NCC content, NCC began to accumulate on the nanofiber membrane surface, and formed a NCC dense layer gradually. As shown in Fig. 2d, f and h, in the surface of $\mathrm{N}-2$, there appeared obvious EVOH nanofibers, almost the NCC were loaded in the voids, while in the surface of $\mathrm{N}-3$, there covered smooth NCC, and the coating layer seemed more obvious in the surface of $\mathrm{N}-4$. Finally, NCC/EVOH/PET sandwich-style membrane was fabricated via coating and deposition the barrier layer (NCC) on the surface of $\mathrm{EVOH}$ nanofiber membrane scaffold supported on PET nonwoven fabric. NCC layer as a barrier layer has small and uniform pore size. In addition, according to the section picture, the NCC only filled the voids on the surface of membrane, and reduced the surface pore size but not affect the continuous pore structure.

\subsection{Wettability of NCC/EVOH composite nanofiber membrane}

Water contact angle is one of the important judgments for the surface wettability of membrane material to water. The higher 

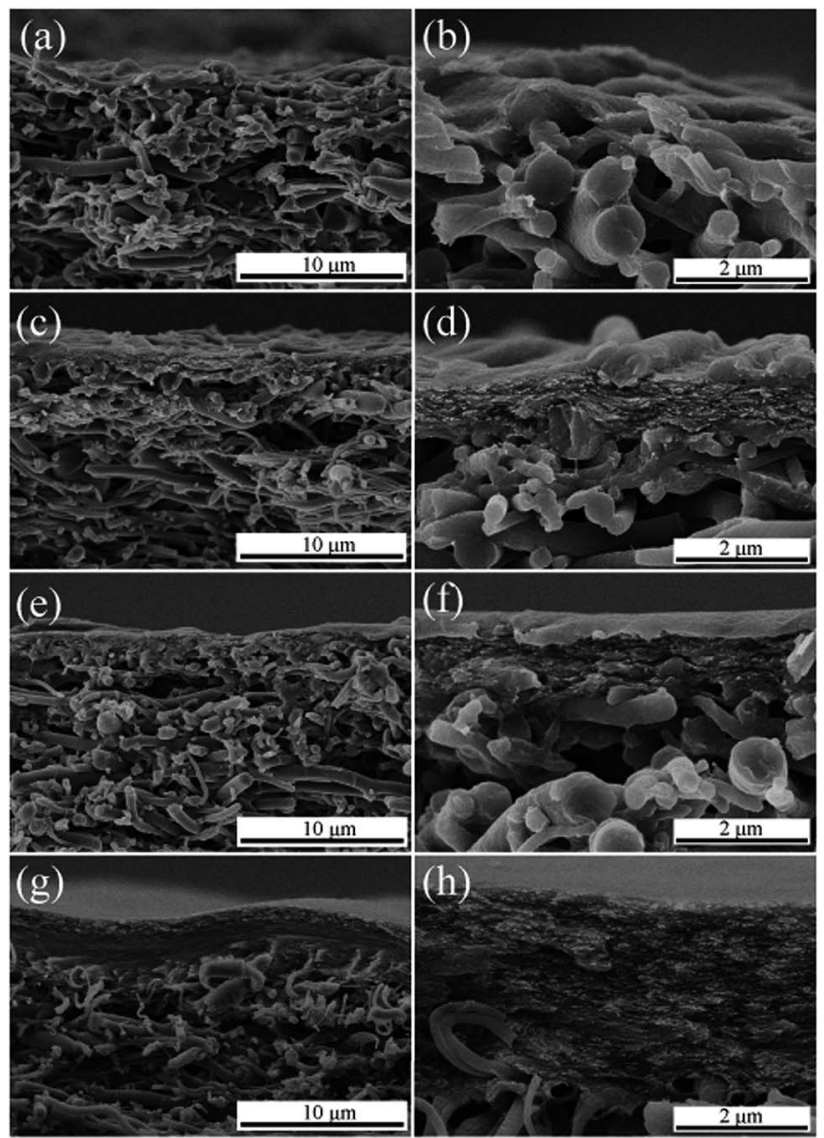

Fig. 2 SEM images of cross sectioned $\mathrm{NCC} / \mathrm{EVOH}$ nanofiber composite membrane (a) and (b) N-1, (c) and (d) N-2, (e) and (f) N-3, (g) and (h) N-4.

affinity of water to hydrophilic membrane surface can be prone to the formation of hydration layer on the membrane surface, which may reduce membrane fouling by preventing hydrophobic components. ${ }^{41}$ Fig. 3 shows the water contact angles of N/E-NCMs with various NCC content. With the increasing of NCC content, the water contact angle of composite membrane decreased gradually. EVOH nanofiber membrane without NCC showed hydrophilicity to water droplets, forming a contact

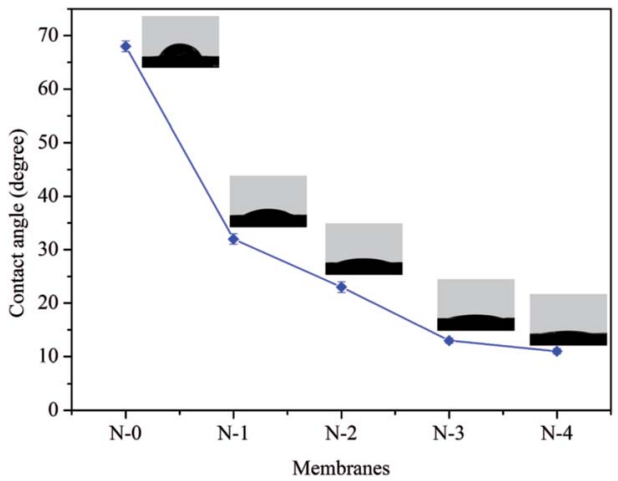

Fig. 3 Contact angel images of $\mathrm{NCC} / \mathrm{EVOH}$ nanofiber composite membranes $\mathrm{N}-0, \mathrm{~N}-1, \mathrm{~N}-2, \mathrm{~N}-3$ and $\mathrm{N}-4$. angle of $68^{\circ}$. The water contact angles of $\mathrm{N}-1, \mathrm{~N}-2, \mathrm{~N}-3, \mathrm{~N}-4$ membranes were $32^{\circ}, 23^{\circ}, 13^{\circ}, 11^{\circ}$, respectively, which was attributed to the nanocellulose crystals with small size and large surface area possessed abundant hydroxyl. This remarkable enhancement in the hydrophilicity could improve the water permeability of membrane material.

\subsection{Pore size and pore size distribution}

Pore size and pore size distribution are the important parameters of membrane material and play a critical role in the application. PET plays a supporting role in the NCC/EVOH nanofibers composite membrane, and $\mathrm{EVOH}$ nanofibers is the key filtering material, NCC forming the NCC barrier layer in $\mathrm{N}-4$ is for enhancing the hydrophilicity and as a barrier layer. Fig. 4 displays the pore size and pore size distribution of N/E-NCM with various NCC contents. It is worth noting that the pore size of $\mathrm{N}-1$ membrane was shown in the range of $0.15-1.10 \mu \mathrm{m}$, and decreased with the increasing of NCC contents. In addition, $80 \%$ present of the pores are concentrated between $0.15-0.50$ $\mu \mathrm{m}$. Table 1 summarized the maximum pore size, mean pore size and minimum pore size. As listed in Table 1, the average pore size of $\mathrm{N}-0, \mathrm{~N}-1, \mathrm{~N}-2, \mathrm{~N}-3, \mathrm{~N}-4$ membranes were $0.38 \mu \mathrm{m}$, $0.32 \mu \mathrm{m}, 0.29 \mu \mathrm{m}, 0.24 \mu \mathrm{m}, 0.22 \mu \mathrm{m}$, respectively. It can be seen from Fig. $2 \mathrm{~h}$ that the thickness of NCC was less than $2 \mu \mathrm{m}$, while the thickness of EVOH nanofiber membranes in this work were about $100 \mu \mathrm{m}$. The average diameter of EVOH nanofiber was about $300 \mathrm{~nm}$, a large number of $\mathrm{EVOH}$ nanofibers formed dense microfiltration membrane with small pore size $(0.38 \mu \mathrm{m})$. After coating and deposition a very thin NCC film compared to EVOH nanofiber membranes on the surface of EVOH nanofiber membrane, result in the average pore size decreased from 0.38 $\mu \mathrm{m}$ to $0.22 \mu \mathrm{m}$, maximum pore size decreased from $1.28 \mu \mathrm{m}$ to $0.78 \mu \mathrm{m}$, minimum pore size decreased from $0.2 \mu \mathrm{m}$ to $0.1 \mu \mathrm{m}$. It is clearly visible that the adding of NCC reduced the pore size gradually because of the small diameter of NCC, making N/ENCM a good candidate for filtration.

\subsection{Stress-strain properties}

The mechanical property was also a significant factor in water filtration. The typical tensile stress-strain curves of N/E-NCM with various NCC contents were shown in Fig. 5 . It is clearly shown that tensile stress of N/E-NCMs increased gradually with the increasing of NCC contents as expected. As I mentioned in the above, the NCC film on the surface of EVOH nanofiber membrane compared to EVOH nanofiber membranes was quite thin, so there was no dramatic increase. The $\mathrm{N}-0, \mathrm{~N}-1, \mathrm{~N}-2, \mathrm{~N}-3$, $\mathrm{N}-4$ membranes possessed the tensile stress of 9.969, 10.222, $10.573,10.736$ and $12.991 \mathrm{MPa}$, which could be owing to the strengthening interaction from hydrogen bond exiting between nanofibers and NCCs.

\subsection{Water flux}

3.5.1 Effect of NCC content. The water flux of nanofiber membranes affects its liquid filtration performance. In the present work, water flux through the N/E-NCM with various NCC contents was investigated under operation pressure of 

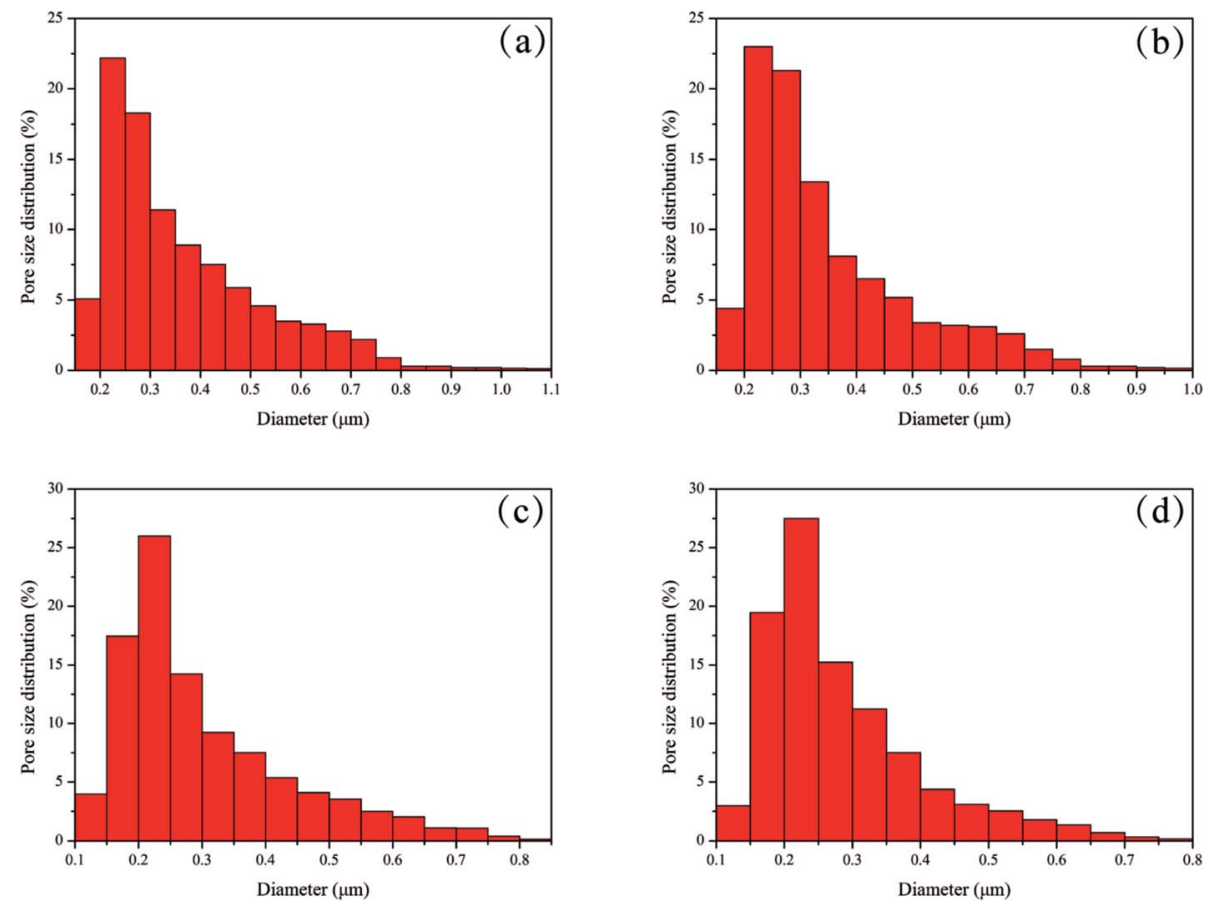

Fig. 4 The pore size distribution of $\mathrm{NCC} / \mathrm{EVOH}$ nanofiber composite membrane (a) N-1, (b) N-2, (c) N-3, (d) N-4.

Table 1 The pore size properties of NCC/EVOH nanofiber composite membrane

\begin{tabular}{llll}
\hline Sample & $\begin{array}{l}\text { Maximum pore } \\
\text { size }(\mu \mathrm{m})\end{array}$ & $\begin{array}{l}\text { Mean pore } \\
\text { size }(\mu \mathrm{m})\end{array}$ & $\begin{array}{l}\text { Minimum pore } \\
\text { size }(\mu \mathrm{m})\end{array}$ \\
\hline $\mathrm{N}-0$ & 1.28 & 0.38 & 0.20 \\
$\mathrm{~N}-1$ & 1.06 & 0.32 & 0.18 \\
$\mathrm{~N}-2$ & 0.97 & 0.29 & 0.17 \\
$\mathrm{~N}-3$ & 0.84 & 0.24 & 0.13 \\
$\mathrm{~N}-4$ & 0.78 & 0.22 & 0.10 \\
\hline
\end{tabular}

0.1 MPa. The Effect of NCC content on the N/E-NCM water flux was displayed in Fig. 6. It is worth noting that as the NCC content increased to $15 \mathrm{mg} \mathrm{cm}^{-3}$, the N/E-NCM water flux decreased sharply from $1888 \mathrm{~L} \mathrm{~m}^{-2} \mathrm{~h}^{-1}$ to $932 \mathrm{~L} \mathrm{~m}^{-2} \mathrm{~h}^{-1}$. This

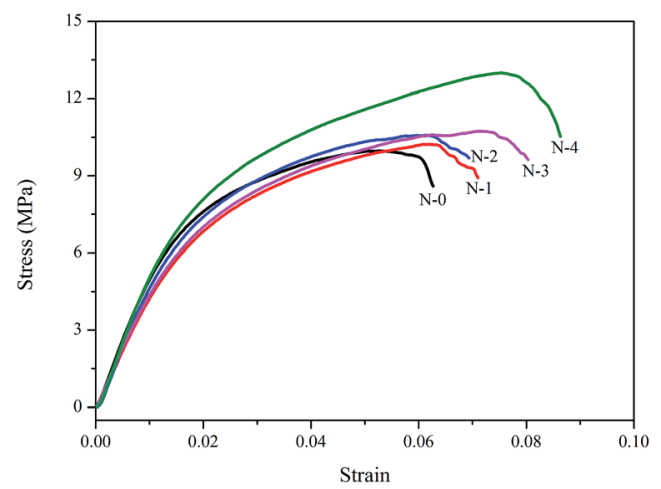

Fig. 5 Stress-strain properties of $\mathrm{NCC} / \mathrm{EVOH}$ nanofiber composite membranes.

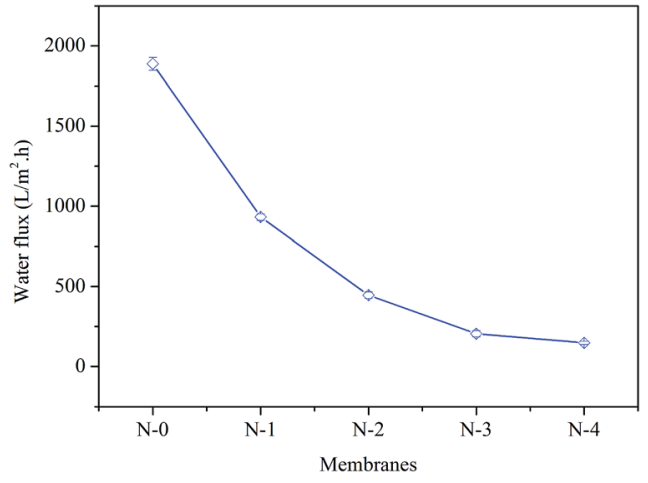

Fig. 6 Effect of NCC content on the water flux of NCC/EVOH composite nanofiber membranes.

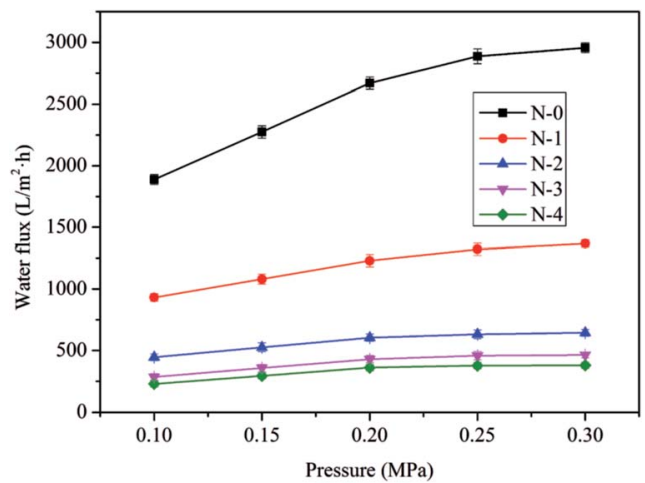

Fig. 7 Effect of pressure on the pure water flux of $\mathrm{NCC} / \mathrm{EVOH}$ composite nanofiber membranes. 


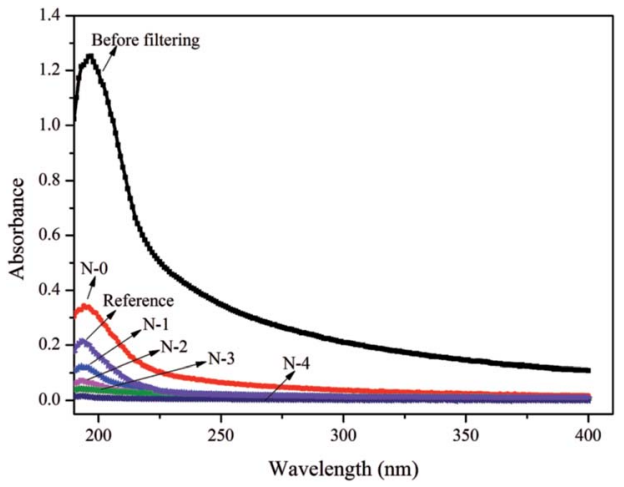

Fig. 8 UV absorption spectrogram of oil-water emulsion before and after filtering by $\mathrm{NCC} / \mathrm{EVOH}$ composite nanofiber membranes and reference membrane.

result was consistent with the previous conclusion that the deposition of NCC on the EVOH nanofiber membrane surface formed a NCC barrier layer, providing smaller water channels. The pore size of N/E-NCM decreased with the increasing of NCC contents, resulting in a higher resistance, reducing the infiltration rate and the water flux. However, as the NCC content increased from $20 \mathrm{mg} \mathrm{cm}^{-3}$ to $30 \mathrm{mg} \mathrm{cm}^{-3}$, the pore size of N/ENCM decreased slightly with the increasing of NCC contents, result in the N/E-NCM water flux decreased slightly. The water flux of N/E-NCM was also affected by the water wettability.

3.5.2 Effect of pressure on the pure water flux. Operation pressure is one of the most significant factors for the pure water flux, thus the experiment was carried out to investigate the effect of operation pressure on the pure water flux of N/M-NCM, and the results were presented in Fig. 7. It is noteworthy that the pure water flux of N/E-NCM was increased with the increasing of operation pressure. Moreover, at low pressure, with the increasing of operation pressure, the pure water flux of composite membrane increased greatly. As the pressure higher than 0.20 MPa, the pure water flux of composite membrane increased slightly. The results was consistent with the previous literature that the membrane filtration flux increased linear with low pressure, low liquid concentration or high flow rate. ${ }^{42-44}$ In addition, as the NCC content increased in a range, the influence of the pressure on the pure water flux of the composite membrane was gradually decreased. It was because that the pure water flux of the composite membrane was
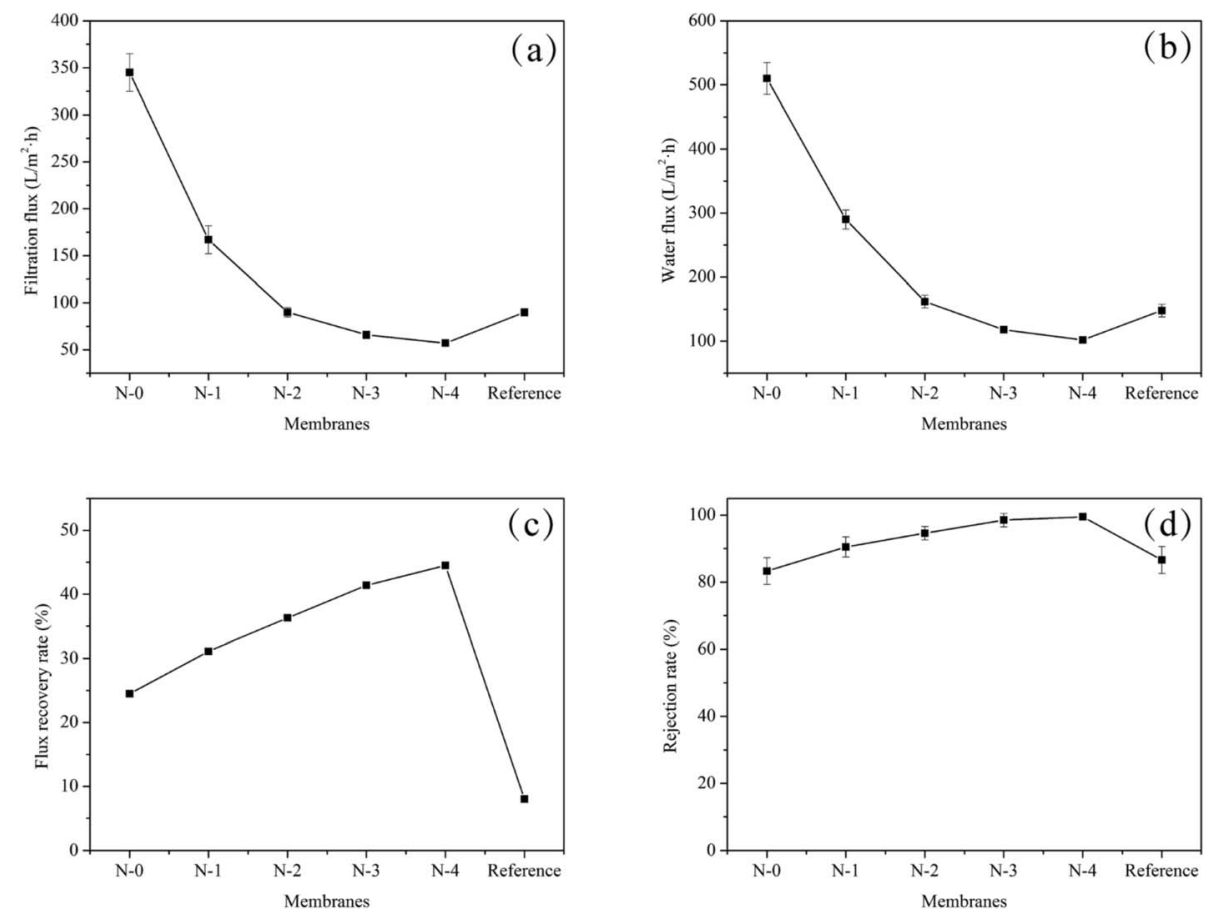

Fig. 9 Filtering effect of NCC/EVOH composite nanofiber membranes and reference film for oil-water emulsion at $0.1 \mathrm{MPa}$.

Table 2 Filtering effect of NCC/EVOH composite nanofiber membrane (N-4) for oil-water emulsion under different pressure

\begin{tabular}{|c|c|c|c|c|c|}
\hline $\begin{array}{l}\text { Operating pressure } \\
\text { (MPa) }\end{array}$ & $\begin{array}{l}\text { Water flux before } \\
\text { separation }\left(\mathrm{L} \mathrm{m}^{-2} \mathrm{~h}^{-1}\right)\end{array}$ & $\begin{array}{l}\text { Filtration flux } \\
\left(\mathrm{L} \mathrm{m}^{-2} \mathrm{~h}^{-1}\right)\end{array}$ & $\begin{array}{l}\text { Water flux after separation } \\
\left(\mathrm{L} \mathrm{m}^{-2} \mathrm{~h}^{-1}\right)\end{array}$ & $\begin{array}{l}\text { Flux recovery } \\
\text { rate }(\%)\end{array}$ & $\begin{array}{l}\text { Rejection rate } \\
(\%)\end{array}$ \\
\hline 0.10 & 229 & 57 & 102 & 44.5 & 99.5 \\
\hline 0.20 & 361 & 112 & 176 & 48.8 & 99.4 \\
\hline 0.25 & 378 & 109 & 173 & 45.8 & 99.6 \\
\hline
\end{tabular}


determined by operation pressure and water wettability. The increasing of applied pressure would lead to more impurities trapped in the membranes, while the NCC with high water affinity could reduce membrane fouling by preventing hydrophobic components.

\subsection{The performance of oil-water separation}

In the present work, the oil-water separation experiments were carried out to systematically study the relation between the structure of N/E-NCM and filtration performance, and evaluate filtration capability of N/E-NCM. The water flux device designed by ourselves was used to examine the rejection rate of the membrane to oil-water emulsion. Fig. 8 revealed the UV absorption spectrogram of the oil-water emulsion before and after filtration by N/E-NCM and reference membrane. As shown in Fig. 8, the absorbance of oil-water emulsion after filtration dropped seriously by $\mathrm{N}-3$ and $\mathrm{N}-4$, and closed to 0.01 . According to the eqn (2), the results revealed that the $\mathrm{N}-4$ rejection rate to oil-water emulsion was above $99.5 \%$. In addition, water flux of N/E-NCM and reference film during the oil-water separation process was investigated, and all the results were shown in Fig. 9. It is obvious that the flux recovery rate and the rejection rate of N/E-NCM were $44.5 \%$ and $99.5 \%$, higher than those of the reference film, which were $8.0 \%$ and $86.6 \%$. In combination with the good mechanical properties and high filtration performance, it is feasible to achieve a low cost and versatile nanofibers based oil-water emulsion filtration membrane.

Nevertheless, the N/E-NCM had high rejection rate of $99.5 \%$ at $0.1 \mathrm{MPa}$ operating pressure, while the filtration flux was merely $57 \mathrm{~L} \mathrm{~m}^{-2} \mathrm{~h}^{-1}$, affecting the operating rate. In order to improve the operating rate, the experiment was also carried out to investigate the effect of the operating pressure on the filtration flux, and the results were shown in Table 2 . It could be seen that the filtration flux of N/E-NCM increased gradually with the operating pressure increasing from $0.1 \mathrm{MPa}$ to $0.2 \mathrm{MPa}$. However, as the pressure further increased, the filtration flux of N/E-NCM decreased. Previous lectures suggested that the filtration flux of separation membrane linearly increased with increasing the filtration pressure in a certain range. While the filtration pressure beyond the range, the filtration flux tends to decrease owing to the filter cake and the membrane pore blockage formed on the membrane surface due to concentration polarization. ${ }^{45}$ It is worth noting that the filtration rate of prepared membranes for oil-water emulsion was above $99 \%$. Thus the operating pressure could be increased properly, and the operation pressure of $0.2 \mathrm{MPa}$ was optimized to increase filtration rate.

\section{Conclusion}

NCC/EVOH nanofiber composite membranes (N/E-NCM) were prepared by deposition NCC on the surface of EVOH nanofiber membrane, which was prepared by the melt blending extrusion method. The basic structure properties and oil-water separation performance of composite membranes were investigated. The results shown that the deposited NCC filled on the surface of nanofiber membrane and a little in the voids formed a barrier layer with small pore size, and had no effect on the continuous pore structure of membrane. With the increasing of NCC content, the composite membranes showed an increase of tensile strength (from 9.969 MPa to $12.991 \mathrm{MPa}$ ) and a decrease of contact angle, pore size, and water flux. The water flux and filtration flux of composite membrane could be improved within a certain range by increasing the operation pressure. The N/E-NCM exhibited a higher rejection rate (99.5\%) and stability of filtration flux than unmodified EVOH nanofiber membrane and the commercial micro-filtration membrane for the separation of oil-water emulsion. The results indicated that the combination of NCC and EVOH nanofiber membrane making N/E-NCM a good candidate for oil-water emulsion separation.

\section{Acknowledgements}

This research was supported by the National Natural Science Foundation of China (No. 21374015), and the program of Introducing Talents of Discipline to Universities (No. 111-2-04).

\section{References}

1 T. A. Pagano and T. Evans, Oil Gas J., 2010, 108, 104-110.

2 A. Szép and R. Kohlheb, Water Sci. Technol., 2010, 62, 23722380.

3 D. Bhagawan, S. Poodari, S. Golla, V. Himabindu and S. Vidyavathi, Desalin. Water Treat., 2016, 57, 3387-3394.

4 X. Zhu, W. Tu, K.-H. Wee and R. Bai, J. Membr. Sci., 2014, 466, 36-44.

5 C. E. Clark and J. A. Veil, Geosciences, 2009, DOI: 10.2172/ 1007397.

6 A. Idris, I. Ahmed and H. W. Jye, Water Sci. Technol., 2007, 169-177.

7 J. Saththasivam, K. Loganathan and S. Sarp, Chemosphere, 2016, 144, 671-680.

8 M. Obaid, N. A. M. Barakat, O. A. Fadali, M. Motlak, A. A. Almajid and K. A. Khalil, Chem. Eng. J., 2015, 259, 449-456.

9 A. Salahi and T. Mohammadi, Water Sci. Technol., 2010, 62, 245-255.

10 J. G. Fernandes, D. M. Correia, G. Botelho, J. Padrão, F. Dourado, C. Ribeiro, S. Lanceros-Méndez and V. Sencadas, Polym. Test., 2014, 34, 64-71.

11 X.-J. Han, Z.-M. Huang, C. Huang, Z.-F. Du, H. Wang, J. Wang, C.-L. He and Q.-S. Wu, Polym. Compos., 2012, 33, 2045-2057.

12 Y. Liu, M. Park, H. K. Shin, B. Pant, S.-J. Park and H.-Y. Kim, Mater. Lett., 2014, 132, 23-26.

13 H. Wang, P. Zhang, X. Ma, S. Jiang, Y. Huang, L. Zhai and S. Jiang, J. Hazard. Mater., 2014, 265, 158-165.

14 B. Vazquez, H. Vasquez and K. Lozano, Polym. Eng. Sci., 2012, 52, 2260-2265.

15 A. Valipouri, S. A. H. Ravandi and A. R. Pishevar, Fibers Polym., 2013, 14, 941-949.

16 L. Ren, R. Ozisik and S. P. Kotha, J. Colloid Interface Sci., 2014, 425, 136-142. 
17 M. A. Hammami, M. Krifa and O. Harzallah, J. Text. Inst., 2014, 105, 637-647.

18 Y. Lu, Y. Li, S. Zhang, G. Xu, K. Fu, H. Lee and X. Zhang, Eur. Polym. J., 2013, 49, 3834-3845.

19 J. Zhao, W. Han, H. Chen, M. Tu, R. Zeng, Y. Shi, Z. Cha and C. Zhou, Carbohydr. Polym., 2011, 83, 1541-1546.

20 J. Shao, C. Chen, Y. Wang, X. Chen and C. Du, React. Funct. Polym., 2012, 72, 765-772.

21 J. Shao, C. Chen, Y. Wang, X. Chen and C. Du, Appl. Surf. Sci., 2012, 258, 6665-6671.

22 A. Lu, J. Zhu, G. Zhang and G. Sun, J. Mater. Chem., 2011, 21, 18674.

23 M. Li, X. Xue, D. Wang, Y. Lu, Z. Wu and H. Zou, Desalination, 2013, 329, 50-56.

24 M. Li, R. Xiao and G. Sun, J. Appl. Polym. Sci., 2012, 124, 2836.

25 D. Wang, G. Sun and B.-S. Chiou, Macromol. Mater. Eng., 2007, 292, 407-414.

26 D. Xu, K. Zhu, X. Zheng and R. Xiao, Ind. Eng. Chem. Res., 2015, 54, 6836-6844.

27 H. Wang and R. Xiao, Polym. Adv. Technol., 2012, 23, 508515.

28 P. Zhang, D. Xu and R. Xiao, J. Appl. Polym. Sci., 2015, 132, 42184.

29 X. Lin, M. Yang, H. Jeong, M. Chang and J. Hong, J. Membr. Sci., 2016, 506, 22-30.

30 H. Zhu and Z. Guo, J. Bionic Eng., 2016, 13, 1-29.

31 Y. Zhu, F. Zhang, D. Wang, X. F. Pei, W. Zhang and J. Jin, J. Mater. Chem., 2013, 1, 5758-5765.
32 L. Zhang, Y. Zhong, D. Cha and P. Wang, Sci. Rep., 2013, 3, 670-692.

33 F. E. Ahmed, B. S. Lalia, N. Hilal and R. Hashaikeh, Desalination, 2014, 344, 48-54.

34 L. Brinchi, F. Cotana, E. Fortunati and J. M. Kenny, Carbohydr. Polym., 2013, 94, 154-169.

35 J. Lamaming, R. Hashim, O. Sulaiman, C. P. Leh, T. Sugimoto and N. A. Nordin, Carbohydr. Polym., 2015, 127, 202-208.

36 J. P. F. Lagerwall, C. Schütz, M. Salajkova, J. Noh, J. Hyun Park, G. Scalia and L. Bergström, NPG Asia Mater., 2014, 6, 80.

37 S. Fujisawa, T. Saito, S. Kimura, T. Iwata and A. Isogai, Biomacromolecules, 2013, 14, 1541-1546.

38 V. Rubentheren, T. A. Ward, C. Y. Chee and P. Nair, Cellulose, 2015, 22, 2529-2541.

39 H.-M. Ng, L. T. Sin, T.-T. Tee, S.-T. Bee, D. Hui, C.-Y. Low and A. R. Rahmat, Composites, Part B, 2015, 75, 176-200.

40 N. Rescignano, E. Fortunati, S. Montesano, C. Emiliani, J. M. Kenny, S. Martino and I. Armentano, Carbohydr. Polym., 2014, 99, 47-58.

41 X. Zhu, W. Tu, K.-H. Wee and R. Bai, J. Membr. Sci., 2014, 466, 36-44.

42 M. Li, D. Wang, R. Xiao, G. Sun, Q. Zhao and H. Li, Sep. Purif. Technol., 2013, 116, 199-205.

43 X. Zhang, B. Lin, K. Zhao, J. Wei, J. Guo, W. Cui, S. Jiang, D. Liu and J. Li, Desalination, 2015, 365, 234-241.

44 R. Wang, Y. Liu, B. Li, B. S. Hsiao and B. Chu, J. Membr. Sci., 2012, 392-393, 167-174.

45 C. Tang and V. Chen, Desalination, 2002, 143, 11-20. 